\title{
Friedrich Melchior Grimm, Correspondance littéraire
}

\section{Paola Sosso}

\section{(2) OpenEdition}

\section{Journals}

Édition électronique

URL : http://journals.openedition.org/studifrancesi/9228

DOI : 10.4000/studifrancesi.9228

ISSN : 2427-5856

\section{Éditeur}

Rosenberg \& Sellier

\section{Édition imprimée}

Date de publication : 1 juin 2008

Pagination : 191

ISSN : 0039-2944

\section{Référence électronique}

Paola Sosso, «Friedrich Melchior Grimm, Correspondance littéraire », Studi Francesi [En ligne], 154 (LII ]

I) | 2008, mis en ligne le 30 novembre 2015, consulté le 09 janvier 2021. URL : http://

journals.openedition.org/studifrancesi/9228 ; DOI : https://doi.org/10.4000/studifrancesi.9228

Ce document a été généré automatiquement le 9 janvier 2021.

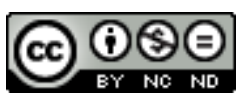

Studi Francesi è distribuita con Licenza Creative Commons Attribuzione - Non commerciale - Non opere derivate 4.0 Internazionale. 


\title{
Friedrich Melchior Grimm, Correspondance littéraire
}

\author{
Paola Sosso
}

\section{RÉFÉRENCE}

FRIEDRICH MELCHIOR GRIMM, Correspondance littéraire, édition critique par Robert GRANDEROUTE, tome II, 1755, Ferney-Voltaire, Centre International d'étude du XVIII ${ }^{\mathrm{e}}$ siècle, 2006, pp. 305.

1 L'année 1755 est sans aucun doute marquée par la mort brutale de Friesen, âgé de vingt-sept ans, dont Grimm était le secrétaire et auquel le liait une profonde amitié. La rédaction et l'expédition de quelques feuilles en sont par conséquent en partie bouleversées, et la vie de Grimm de même: il devient en effet secrétaire de la maison d'Orléans. Montesquieu meurt en février «sans que le public s'en soit, pour ainsi dire, aperçu» (15 février, p. 54): son convoi n'est en effet suivi que de Diderot. Cette même année paraît le deuxième discours de Rousseau, dans lequel, écrit Grimm, «les vues sont grandes, fines, neuves et philosophiques» mais «la vérité outrée n'est plus vérité, et rien n'est plus contraire à ses intérêts [...] que l'esprit de système» (15 juillet, p. 147). En septembre sort le $\mathrm{V}^{\mathrm{e}}$ tome de l'Encyclopédie, tandis que vers la fin de l'année paraît le Traité des animaux de Condillac, «ouvrage tout entier contre M. de Buffon» $\left(1^{\mathrm{er}}\right.$ novembre, p. 230), comme le remarque Grimm dans ses dernières feuilles. À signaler aussi, dans ce deuxième volume, le fait que certaines catégories de livres sont encore une fois délaissées par le rédacteur: à savoir, les ouvrages de théologie, de religion, de droit et de grammaire: cela correspond évidemment aux orientations de Grimm mais également à l'attente de ses abonnés.

2 L'apparat critique qui accompagne les feuilles de la Correspondance littéraire permet encore une fois de mesurer le décalage avec les autres périodiques de l'époque: les feuilles de Grimm se montrent toujours nouvelles et hardies et elles arrivent parfois à corriger, plutôt qu'à compléter, les autres revues, dans leur désir évident de semer les 
idées nouvelles. Pour ce qui est des abonnés de cette année, on retrouve ceux de 1754 . Une importante nouveauté reste encore à souligner: pour donner du prix à son ouvrage, Grimm insère plusieurs fois des contributions de Diderot (dont deux ayant trait à la peinture) de même que des textes d'auteurs et de petites pièces en vers courant dans les salons. Le texte de base pour ce volume est fourni par le manuscrit envoyé à la duchesse de Saxe Gotha. À la fin de l'ouvrage on retrouvera comme annoncé dès le premier volume l'Index des titres, des incipit des pièces en vers et un index général. 